\title{
A tecnologia do motor elétrico para o ensino de Eletromagnetismo numa abordagem problematizadora
}

Cristina Fátima de Jesus Silva Pires

Paulo Celso Ferrari

José Rildo de Oliveira Queiroz

\section{Resumo}

Neste trabalho discutimos o desenvolvimento de aulas dialógicas e problematizadas por meio de um objeto tecnológico com o objetivo de investigar suas contribuições para o ensino de Eletromagnetismo.Para tanto desenvolvemos a estratégia dos três momentos pedagógicos: problematização inicial, organização do conhecimento e aplicação do conhecimento.A pesquisa foi desenvolvida com estudantes do 3ㅇ ano do Ensino Médio de uma escola particular.Trata-se de uma pesquisa qualitativa cujos resultados foram obtidos da análise de conteúdo de um diário de campo e das respostas a um questionário com questões abertas. Concluímos que o objeto tecnológico com abordagem problematizadora mobiliza a curiosidade epistemológica, promove o estabelecimento do diálogo, revela o aspecto aplicado do conhecimento científico e facilita a compreensão conceitual.

Palavras-chave: equipamento gerador; eletromagnetismo; problematização.

\section{Abstract \\ The electric motor technology in the teaching of Electromagnetism in a problem-posing approach}

We discuss the development of dialogical and problem-posing lessons by a technological object in order to investigate its contributions to the teaching of Electromagnetism. Therefore we developed the strategy of the three pedagogical moments: initial problem-posing, knowledge organization and knowledge application. The research was conducted with students of the 3rd year of high school from a private school. This is a qualitative research whose results were obtained from the content analysis of a diary and answers to a questionnaire with open questions. We conclude that the technological object with problem-posing approach mobilizes epistemological curiosity, promotes the dialogue establishment, reveals the applied aspect of scientific knowledge and facilitates conceptual understanding.

Key words: generating equipment; electromagnetism; problem-posing. 


\section{Introdução}

A escola atual frequentemente promove um ensino de Física com a apresentação de leis e conceitos que nem sempre têm significado no cotidiano do educando. Um ensino de mera aplicação de fórmulas, baseado em memorização e resolução de problemas em situações artificiais, que pouco tem a ver com a realidade do estudante. Trata-se de uma didática repetitiva, voltada para o acúmulo de informações que, na melhor das hipóteses, desenvolve apenas habilidades operacionais com um conhecimento científico carente de contextualização. Há uma forte crítica ao ensino de Física por "transmissão" (CACHAPUZ, 2000), considerado distante demais ou mesmo desligado dos fenômenos e das situações que constituem o universo dos estudantes. A esta forma de ensino Freire (2008) denomina "educação bancária", pois o estudante é concebido como um balde vazio onde se depositam os conhecimentos. Com isso, verifica-se um desinteresse dos estudantes e uma grande dispersão nas aulas de Física.

Em geral, os estudantes tem dificuldade de relacionar a Física escolar com seu cotidiano e/ou com a Tecnologia (RICARDO e FREIRE, 2007). Os próprios professores também expressam essa dificuldade (RICARDO; CUSTÓDIO e REZENDE JUNIOR, 2007). Analisando o tratamento dedicado ao tema "Geradores Elétricos", Ribeiro, Rezende Júnior e Nascimento (2010) concluíram que os livros didáticos selecionados pelo Programa Nacional do Livro Didático para o Ensino Médio em 2006 apresentam uma compreensão restrita do que seja Tecnologia. Esforços recentes de se trabalhar os conteúdos científicos vinculados ao universo do estudante mostram que neste nível de ensino é possível uma efetiva aproximação entre o modelo científico e sua possibilidade de aplicação em situações reais(PIETROCOLA, 2005).

Neste trabalho discutimos o desenvolvimento de aulas dialógicas e problematizadas por meio de um objeto tecnológico, concebido como "equipamento gerador" (AUTH et al., 1995), com o objetivo de investigar as contribuições desta abordagem para o ensino de Eletromagnetismo.Para tanto, recorremos aos três momentos pedagógicos, que indicamcomo eixo de atuação a problematização (DELIZOICOV, 1991), caracterizada por constantes diálogos sobre um tema pré-determinado, procurando despertar a curiosidade, de forma a incentivar continuamente a participação de todos para a construção do conhecimento no processo de ensino e aprendizagem.

\section{Tecnologia e Diálogo}

Participando da sociedade e por meio de suas experiências os indivíduos criam sua visão, mesmo que de senso comum, de mundo. A escola tem o papel de questionar o conhecimento de senso comum e introduzir o conhecimento científico, sistematizando didaticamente as experiências coletivas (PIETROCOLA, 2005) e tornar "significativo esse aprendizado científico"(GREF, 1995, p. 19). A escola precisa inovar constantemente seus métodos de ensino 
para acompanhar as crescentes mudanças ocorridas na sociedade, particularmente no que diz respeito à Tecnologia. Precisa, cada vez mais, tratar de questões reais, como o levantamento de problemas e soluções geradas pela introdução de uma determinada tecnologia no cotidiano dos estudantes.

A Tecnologia estabelece vínculos com a realidade, uma vez que "terá que ser entendida como a utilização de conhecimentos científicos para satisfação das autênticas necessidades materiais de um povo" (VARGAS, 2003, p. 183). É quando os saberes específicos da Física, com seu inerente tratamento matemático, deixam de ser um fim em si mesmo e passam a ser um instrumento para a compreensão do mundo:

"A Física, instrumento para a compreensão do mundo em que vivemos, possui também uma beleza conceitual ou teórica, que por si poderia tornar seu aprendizado agradável. Esta beleza, no entanto, é comprometida pelos tropeços num instrumental matemático com o qual a Física é frequentemente confundida [...]".(GREF, 1995, p. 19).

Além da beleza conceitual ou teórica, a Física possui um aspecto aplicado, presente no desenvolvimento tecnológico, que possibilita a interlocução com estudantes, principalmente quando se aproxima do seu universo cultural. Podemos aproximar a física escolar do universo cultural dos estudantes abordando questões tecnológicas:

"O desenvolvimento dos fenômenos elétricos e magnéticos, por exemplo, pode ser dirigido para a compreensão dos equipamentos elétricos que povoam nosso cotidiano, desde aqueles de uso doméstico aos geradores e motores de uso industrial, provendo competências para utilizá-los, dimensioná-los ou analisar condições de sua utilização. Dessa forma, o sentido para o estudo da eletricidade e do eletromagnetismo pode ser organizado em torno de equipamentos elétricos e telecomunicações". (BRASIL, 2002, p. 70).

$\mathrm{Na}$ literatura científica encontramos alguns artigos que discutem a utilização do motor elétrico no ensino de Eletromagnetismo (BENDER; SBARDELOTTO e MAGNO, 2004; MONTEIRO et al., 2010; SILVA e LABURÚ, 2009). Bender, Sbardelotto e Magno (2004) propõema utilização do motor elétrico para a construção de dois dispositivos: um anemômetro e um contador de freqüência. Monteiro et al (2010) apresentam o motor elétrico como exemplo de montagem experimental simples com orientações baseadas na teoria de Vigotski. Silva e Laburu (2009) sugerem duas formas de montagem de motor elétrico, como propostas por Michael Faraday, para demonstrações em museus e laboratórios didáticos. No presente trabalho utilizamos o motor elétrico como exemplo de objeto tecnológico presente no cotidiano dos estudantes.

Os objetos tecnológicos podem contribuir para o diálogo professor-aluno e aluno-aluno, desde que transformados em "equipamentos geradores", ou seja, utilizados para gerar temáticas 
no desenvolvimento deaulas ou unidades de ensino (AUTH et al., 1995). O uso de sistemas físicos reais como recurso didático, de caráter teórico-experimental,potencializa o diálogo em sala de aula, aproxima o estudante da realidade que o cerca e tem a função pedagógica de propiciar uma melhor compreensão conceitualdas teorias físicas (MION e ANGOTTI, 2004). Os objetos tecnológicos apresentam-se como uma possibilidade para discutir Tecnologia, enquanto atividade de pesquisa com características próprias e implicações sociais, questionando a idéia de que a Tecnologia seja apenas um produto da Ciência que se impõe naturalmente como solução para a melhoria da qualidade de vida (ANGOTTI; DE BASTOS e MION, 2001). No entanto, transformar objetos tecnológicos em equipamentos geradores de aulas ou unidades de ensino "exige que a prática educacional seja viabilizada pelo manuseio reflexivo destes" (DE BASTOS, 1995), ou seja, uma concepção de educação dialógica e problematizadora. Nesta concepção, que tem como base a pedagogia de Freire(2008), com equivalentes no ensino de Física (ANGOTTI, 1982; DELIZOICOV, 1982; MENEZES, 1980), o docente deve se familiarizar com o universo do estudante, conhecendo o que ele pensa sobre algum tema e, após isso, ser capaz de relacionar esseuniverso com os temas inseridos na disciplina, o que é definido por Freire (2008) como processo de codificaçãoproblematização-descodificação.

Uma abordagem experimental dos objetos tecnológicos podedespertar no estudantea curiosidade pelo aprendizado de conceitos científicos, porém, se fundamentada no ensino por transmissão, ou seja, por uma educação bancária, terá um alcance restrito. É sabido que educação bancária não consegue suprir a necessidade do conhecimento crítico. Para que o processo de conhecimento possa fazer sentido para os jovens:

\section{"[...] é imprescindivel que ele seja instaurado por meio de um diálogo constante} entre alunos e professores, mediado pelo conhecimento. E isso somente será possivel se estiverem sendo considerados objetos, coisas e fenômenos que façam parte do universo vivencial do aluno, seja próximo, como carros, lâmpadas ou televisões, seja parte de seu imaginário, como viagens espaciais, naves, estrelas ou o Universo. Assim, devem ser contempladas sempre estratégias que contribuam para esse diálogo". (BRASIL, 2002, p. 83).

O diálogo problematizador irá possibilitar que a "curiosidade ingênua" pelos objetos tecnológicos seja transformada em curiosidade crítica, "epistemológica", uma vez que "a promoção da ingenuidade para a criticidade não se dá automaticamente" (FREIRE, 2007, p. 32). Curiosidade epistemológica é aquela comprometida com a busca do conhecimento científico, que leva a uma ruptura com o senso comum (MAIA e MION, 2005).

No diálogo o indivíduo estimula a sua consciência crítica, pois quem dialoga, dialoga com alguém sobre alguma coisa (FREIRE, 2008). O assunto deste diálogo, esta "alguma coisa", geralmente está relacionada à realidade dos envolvidos. Este diálogo se faz importante para aprendizagem de todos os envolvidos: "Desta maneira, o educador já não é o que apenas educa, 
mas o que, enquanto educa, é educado, em diálogo com o educando que, ao ser educado, também o educa" (FREIRE, 2008, p. 79). Este contexto favorece o pensamento crítico, reflexivo, ou consciência crítica, em que o indivíduo, ao compartilhar suas ideias com as ideias e opiniões de outros, pensa em sua prática, tornando-se um cidadão consciente, despertando para o ensinar e o aprender.

A concepção dialógica e problematizadora no Ensino de Ciências orientou a elaboração da estratégia didática conhecida como "três momentos pedagógicos" (DELIZOICOV, 1982, 2008): problematização inicial, organização do conhecimento e aplicação do conhecimento. A problematização inicial caracteriza o momento de ouvir os estudantes e tentar compreender seu universo. É também o momento em que os estudantes são incentivados a ter certa curiosidade sobre o mundo que os cerca. Para Ricardo (2011, p. 42) "a problematização consiste na construção de situações-problemas que irão estruturar as situações de aprendizagem", e uma situação-problema deve ter "o potencial de gerar no aluno a necessidade de apropriação de um conhecimento que ele ainda não tem e que não foi apresentado pelo professor" (DELIZOICOV, 2005, p. 132). Ou seja, não basta colocar o estudante diante da falta de conhecimento, mas face à necessidade de um conhecimento (RICARDO, 2011).Geram-se expectativas no estudante e cabe ao professor aproveitá-las no processo educativo para não fazer do mesmo um motivo de maior distanciamento do estudante para com as aulas - o que é um dos grandes desafios da escola.

$\mathrm{Na}$ organização do conhecimento são introduzidos os conceitos científicos. Com a inquietação provocada pelos problemas levantados inicialmente, o estudante compreende por que o professor irá ensinar determinados conteúdos e quais as suas intenções com este ensino. É nesse momento que "os conhecimentos selecionados como necessários para a compreensão dos temas e da problematização inicial são sistematicamente estudados sob a orientação do professor" (DELIZOICOV, 2005, p. 143).

Uma vez introduzidos os conceitos, no momento da aplicação do conhecimento os estudantes poderão participar da resolução dos problemas levantados na problematização inicial. Além disso, esse terceiro momento:

"Destina-se, sobretudo, a abordar sistematicamente o conhecimento que vem sendo incorporado pelo aluno para analisar e interpretar tanto as situações iniciais que determinaram o seu estudo, como outras situações que não estejam diretamente ligadas ao motivo inicial, mas que são explicadas pelo mesmo conhecimento". (ANGOTTI e DELIZOICOV, 1991, p. 131).

Mesmo tendo sido desenvolvido no âmbito da criação de novos currículos, os três momentos pedagógicos tem sido utilizados no planejamento de cursos, unidades e aulas (MUENCHEN e DELIZOICOV, 2010a, 2010b). 


\section{Metodologia da Pesquisa}

Adotamos como estratégia de pesquisa a observação participante em aulas de Física ministradas pela primeira autora deste trabalho. Para a construção dos dados empregamos uma abordagem qualitativa, na qual o "investigador é instrumento principal de investigação e o ambiente natural é a fonte direta dos dados"(BOGDAN e BIKLEN, 1994). Os resultados foram obtidos por análise de conteúdo de dois instrumentos: diário de campo e questionário de avaliação das aulas.

No diário de campo, descritivo e reflexivo, definido como um registro detalhado não só dos sucessos, mas também das dificuldades do processo (BOGDAN e BIKLEN, 1994), foram registradas as impressões da professora pesquisadora em todas as aulas pesquisadas.

Apesar do risco da superficialidade dos dados, como a predominância de descrições e não explicações, optamos pelo uso de questionário com questões abertas"deixando os respondentes livres para responderem da maneira mais apropriada" (MOREIRA e CALEFFE, 2006, p. 98). Oquestionário de avaliação das aulas foi composto por duas questões: 1. Qual a sua opinião sobre as aulas da unidade de motor elétrico? Compare com as aulas das outras unidades.2. Você conseguiria identificar um motor elétrico no seu cotidiano? Cite alguns. A questão 1 teve como objetivo avaliar o papel do objeto tecnológico mediante a abordagem adotada. A questão 2 teve por objetivo verificar se o estudante consegue identificar o objeto tecnológico nos equipamentos presentes em seu cotidiano.

Para a realização desta pesquisa houve autorização prévia do conselho da escola e a professora pesquisadora, sendo titular da cadeira, adotou procedimentos usuais em sala de aula, não havendo riscos relativos à segurança física, psíquica ou moral dos estudantes envolvidos. 0 questionário apresentado garantiu o anonimato e não exigiu dos estudantes nenhuma exposição que pudesse gerar constrangimento, pois foi reflexo exclusivo do processo de ensino e aprendizagem, integrando-se tranquilamente aos demais procedimentos em sala de aula.

Os procedimentos da pesquisa foram desenvolvidos pela primeira autora em uma unidade didática de 10 aulas do quarto bimestre do ano letivo de 2009, com uma turma de 28 estudantes do 3o ano do Ensino Médio do turno matutino de um colégio particular de uma capital brasileira.O tema Eletromagnetismo já estava previsto no programa da disciplina, pois trata-se de uma escola de educação formal. Para o desenvolvimento dos conceitos de Campo Magnético, Força Magnética e Indução Eletromagnética foi escolhido como objeto tecnológicoo Motor Elétrico. Os conceitos de Eletromagnetismo foram desenvolvidos com a aplicação dos três momentos pedagógicos.

Na primeira aula, como parte da problematização inicial, os estudantes foram orientados a dar exemplos de aparelhos elétricos que eles conhecessem de alguma forma. Os nomes citados foram colocados de forma aleatória no quadro negro. Em seguida, eles foram incentivados a 
classificar cada elemento citado em cinco grandes grupos: Aparelhos Resistivos, Motores Elétricos, Fontes de Energia Elétrica, Sistemas de Informação e de Comunicação e Equipamentos Elétricos e Eletrônicos. Esta classificação foi feita também no quadro negro. Os estudantes já dispunham de uma definição para cada um dos cinco grandes grupos anteriores.

$\mathrm{Na}$ segunda aula foi apresentado aos estudantes um motor de liquidificador (Figuras 1a e 1b), escolhido como equipamento gerador a ser trabalhado.

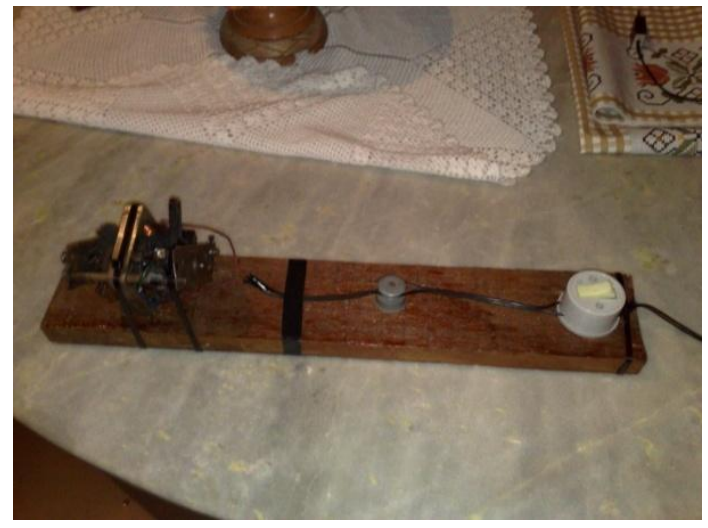

(a)

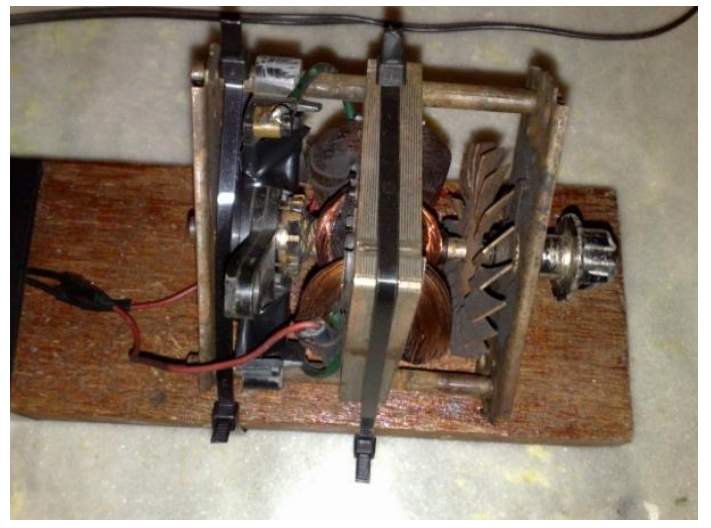

(b)

Figura 1 - (a) Suporte com o motor de liquidificador; (b) Motor de liquidificador.

(Fonte: arquivo pessoal)

Esse motor foi manuseado por todos os estudantes. Em seguida, o motor foi ligado e os estudantes puderam observá-lo em pleno funcionamento.

Após esta atividade foram levantadas questões problematizadoras que levaram os estudantes a pensar sobre seu conhecimento acerca do assunto. As questões problematizadoras foram: a) Como funcionam os motores elétricos? b) De quê estes motores são constituídos? c) Será que podemos construir um motor elétrico?

Com os estudantes predispostos a entender sobre o funcionamento do motor elétrico, foi dado início ao segundo momento, da organização do conhecimento. Assim, durante 4 aulas foram trabalhados os conceitos de Eletromagnetismo para entendimento do motor elétrico, utilizandose do GREF(1995) e do livro texto adotado (PARANÁ, 2003), com os seguintes tópicos:Propriedades dos ímãs, Experiência de Oersted,Força magnética eExperiência de Faraday.

Em complemento às aulas teóricas desenvolvemos as seguintes atividades experimentais:Experiência de Oersted (Figura 2) eGerador de energia (Figura 3). Os equipamentos utilizados nessas atividades foram construídos de forma simples, com material acessível, de forma que os próprios estudantes pudessem confeccioná-los.

Com oequipamentoda Experiência de Oersted (Figuras 2a e 2b) os estudantes puderam observar que a corrente elétrica gera um campo magnético. 


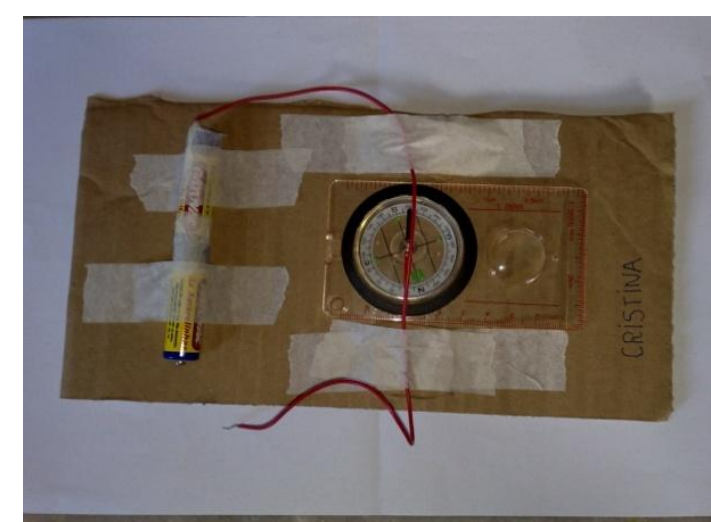

(a)

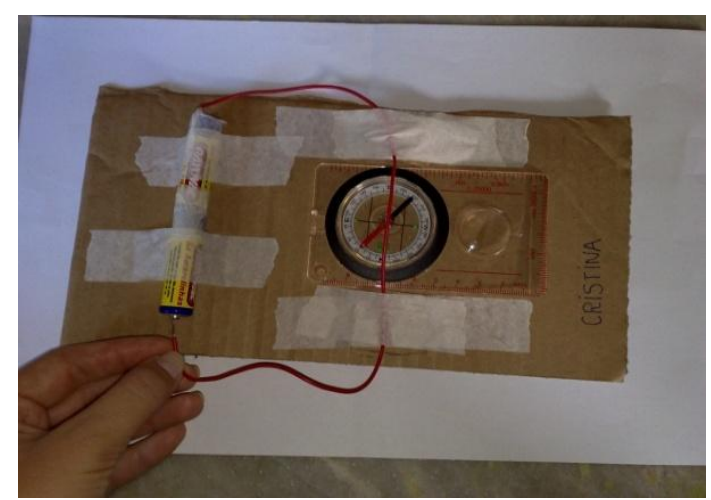

(b)

Figura 2 - Experiência de Oersted: (a) Desligado; (b) Ligado.

(Fonte: arquivo pessoal)

Para exemplificar a Experiência de Faraday(gerador de eletricidade) foi discutido com os estudantes outro arranjo, cujo simples girar da manivela produzia energia elétrica suficiente para acender dois LEDs(Figura 3).

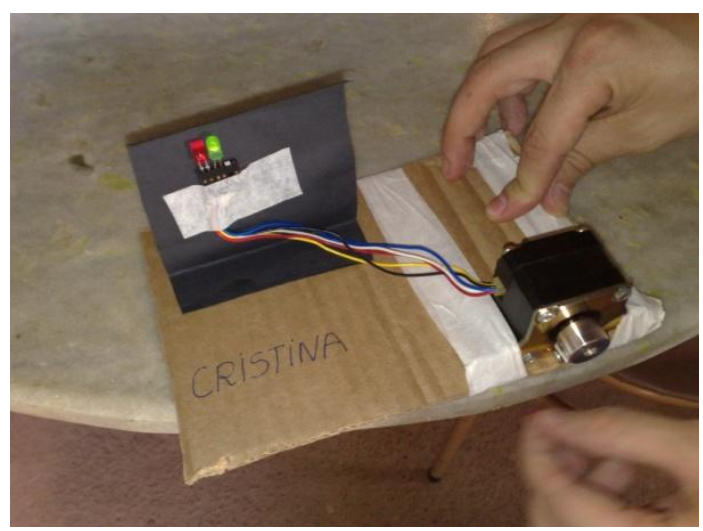

Figura 3 - Gerador de energia

(Fonte: arquivo pessoal)

O dispositivo que continha a manivela é um exemplo de dínamo, obtido de um antigo drive de disquete de computador.

No terceiro momento, de aplicação do conhecimento, retomando os conceitos vistos no momento anterior os estudantes estavam preparados para compreender o funcionamento de um motor elétrico - objeto da problematização inicial. O exemplo apresentado a eles nesse instante, por sua simplicidade, foi um motor a pilha utilizado em carrinhos de brinquedo (Figuras 4a e 4b). Nele pode-se identificar elementos tecnológicos como a parte fixa - chamada de estator - e a móvel - chamada de rotor. 


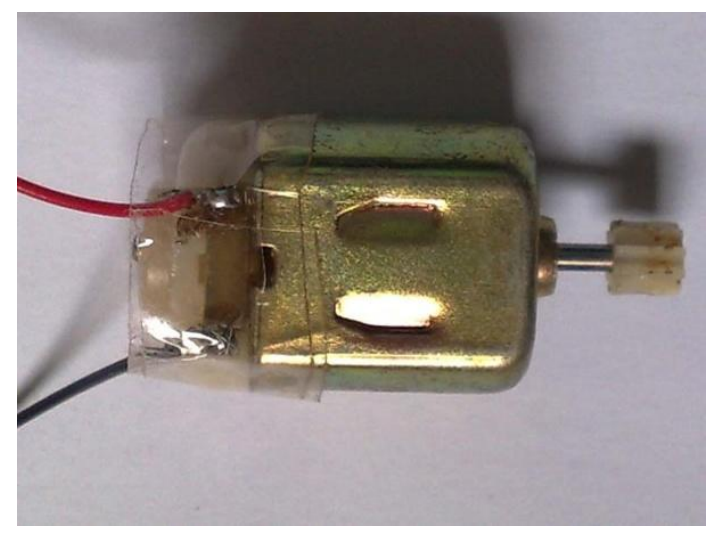

(a)

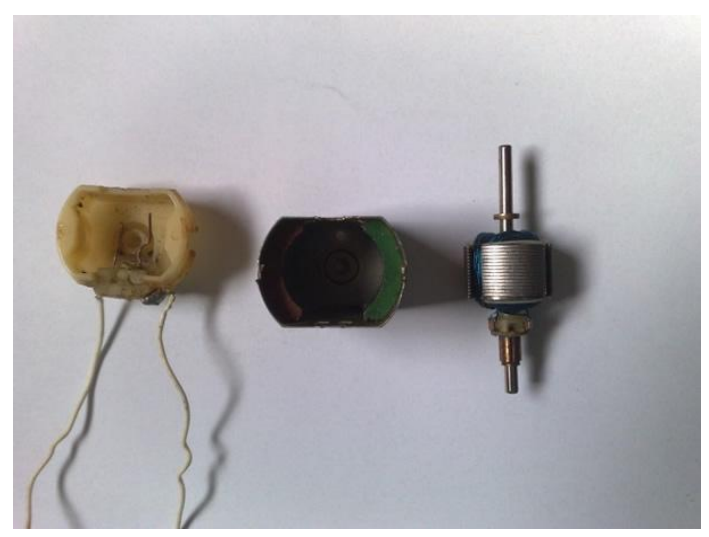

(b)

Figura 4 - Motor de carrinho de brinquedo: (a) Motor completo; (b) Motor desmontado

(Fonte: arquivo pessoal)

Foi possível compreender seu funcionamento quando ligado e, da mesma forma que nas atividades anteriores, todos os estudantes puderam manuseá-lo.

Esclarecendo que os próprios estudantes poderiam construir um motor elétrico substituindo a parte móvel por um enrolamento de fio específico, foi discutido um modelo utilizando o eixo do motor de carrinho de brinquedo(Figura 5).

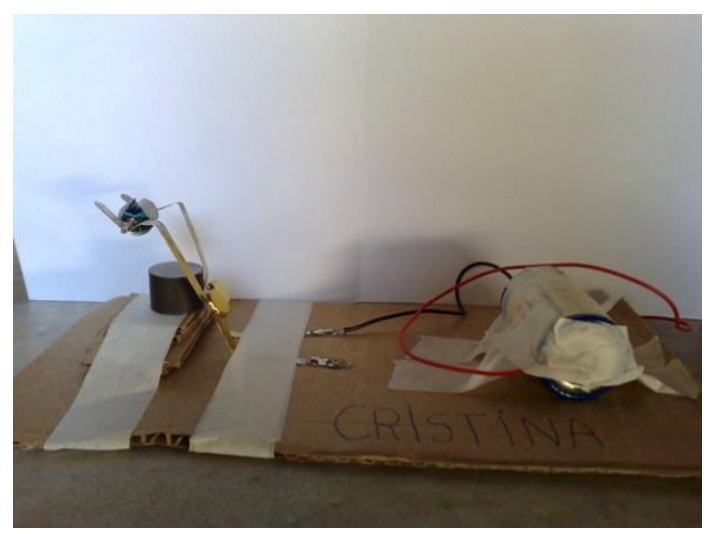

Figura 5 - Motor elétrico

(Fonte: arquivo pessoal)

Finalmente, o motor de liquidificador foi retomado (Figura 1). Novamente ele foi ligado e os estudantes puderam interpretar o seu funcionamento de posse dos conhecimentos adquiridos ao longo do processo.As questões problematizadoras do início das aulas foram retomadas e os próprios estudantes puderam respondê-las.

Além dessas atividades experimentais na segunda aula do terceiro momento os estudantes puderam assistir a uma série de vídeos sobre eletricidade, intitulada "Viagem na Eletricidade" (ROUXEL, 1981), distribuída às escolas pela TV Escola. A apresentação desses vídeos teve como objetivo avaliar o conhecimento adquirido sobre o tema e também discutir outras aplicações desse conhecimento que não estavam ligadas à problematização inicial. 


\section{Análise e Discussão dos Resultados}

Procedemos a análise de conteúdo dos dados segundo critérios de categorização de Bogdan e Biklen (1994). Esse procedimento foi feito da seguinte forma: à medida que os dados foram sendo lidos, destacamos certas palavras, ou frases, a procura de regularidades e padrões. Estas palavras ou frases formaram as categorias de codificação. A seguir os dados foram organizados por categoria, formando unidades de dados e foram eleitas as categorias que melhor respondessem o problema de pesquisa. Para discutir o conteúdo do diário de campo e das respostas ao questionário construímos quatro categorias de análise: curiosidade epistemológica, dialogicidade, aspecto aplicado do conhecimento científico e compreensão conceitual.

\section{Curiosidade epistemológica}

Nesta categoria reunimos elementos que indicam ter sido despertada a curiosidade epistemológica nos estudantes. A principal manifestação de curiosidade se deu por manifestações de interesse, registrados no diário de campo da professora-pesquisadora:

"Mais uma vez, percebi o interesse dos alunos em suas feições e certo entusiasmo dos mesmos - coisa que não é comum numa aula tradicional de Física". (Diário de Campo).

Em resposta à questão 1, um estudante expressou sua percepção do interesse dos colegas:

"Durante $o$ ano as aulas mais interessantes foram as de motor elétrico, pois teve mais interesse dos alunos do que nas outras aulas de matérias diferentes". (Estudante 3).

Em algumas respostas é possível observar que muitas vezes o interesse se deu pela ligação do tema estudado com aplicações no seu cotidiano:

"Eu acho interessante porque convivo com vários motores elétricos, pois eu tendo aula de motor elétrico deve ser bom para eu aprender e saber quando há perigo". (Estudante 7).

"É muito interessante, pelo fato de que nós convivemos e usamos muito, usamos eletrodoméstico praticamente toda hora, geladeira, máquina de lavar etc.". (Estudante 8).

Além dessas manifestações de interesse, foi percebido o compromisso da turma com a aprendizagem, principalmente nas manifestações de dedicação aos estudos:

"Esta aula e a anterior não contaram com experimentos, utilizando apenas o quadro e o livro texto dos alunos, mas, a todo o momento eram feitas 
perguntas sobre temas já estudados e foi visivel a participação dos alunos".(Diário de campo).

Esse interesse declarado e as manifestações observadas nos permitem inferir que a abordagem da tecnologia do motor elétrico despertou a curiosidade epistemológica, ou seja, gerou uma predisposição para a aprendizagem dos conceitos científicos.

\section{Dialogicidade}

Nesta categoria reunimos registros da participação ativa dos estudantes, do estabelecimento do diálogo entre o professor e os estudantes e entre os próprios estudantes. Os trechos a seguir,retirados do diário de campo, sinalizam isto:

"Esta aula foi dinâmica (houve literalmente um movimento na sala, quebrando a ideia do tradicional), com a interação dos alunos através de perguntas, do auxilio à professora com os equipamentos; enfim, com um ótimo aproveitamento dos alunos. A aula passou de forma extremamente rápida". (Diário de campo).

Notamos uma aproximação entre professor e estudante, com um aumento da interação entre ambos, em várias notas do diário de campo:

"Durante a exposição, os alunos fizeram perguntas relacionadas a experiências próprias como "Por que quando há queda de energia em casa, a lâmpada ora fica fraca, ora fica piscando?", que foram respondidas dentro do que eu sabia, $e$ aquelas perguntas que eu não sabia responder no momento, anotei $e$ prometi que levaria a resposta na próxima aula". (Diário de campo).

O professor reconhece dúvidas no processo, tem uma atitude de construção do conhecimento e compromisso com o estudante ao buscar respostas para a próxima aula. Em diversas respostas à questão 1 os estudantes destacaram haver interação entre eles:

"Sobre as aulas de motor elétrico achei bastante interessante, pois todos os alunos interagiram, tornando as aulas mais agradáveis e produtivas". (Estudante 4).

"As aulas de motor elétrico foram mais interativas, os alunos participaram mais, diferente das aulas passadas que era só contas e matéria sem ter interação, as aulas de motor foram mais legais menos cansativa e enjoativa que as outras". (Estudante 5).

Nestas respostas os estudantes destacam um aumento na participação e na interação do grupo devido à abordagem. $O$ estudante 5 compara as aulas desta unidade com as anteriores, 
colocando que nas aulas anteriores não havia interação e que eram cansativas e enjoativas. Uma crítica ao ensino tradicional, meramente expositivo. Com esta interação verificou-se um melhor envolvimento, tendo em vista que tanto os estudantes como o professor demonstraram vontade em persistir na construção do conhecimento.

\section{Aspecto aplicado do conhecimento científico}

Nesta categoria reunimos depoimentos que indicam a percepção do aspecto aplicado do conhecimento científico mediante a identificação do objeto tecnológico (motor elétrico) em diversos equipamentos tecnológicos.Em resposta à questão 2 os estudantes declaram que conseguem distinguir um motor elétrico em seu dia-a-dia e dão vários exemplos corretos:

"Sim, consigo identificar um motor elétrico, liquidificador, geladeira". (Estudante 11).

"Sim, no nosso cotidiano estamos cercado de aparelhos que possuem motor elétrico, tais como a batedeira, ventilador, liquidificador, máquina de lavar, máquina de fazer pão, lava-louça, máquina de costura, escova de dente, serra e furadeira elétrica". (Estudante 12).

Foi possível perceber que alguns estudantes ficaram confusos ao identificar um motor elétrico, pois apesar de não responderem afirmativamente, dão exemplos corretos em seus depoimentos:

"Talvez, pois acredito que por serem motores elétricos a dinâmica é a mesma, portanto, torna-os muito parecidos. Posso reconhecer o motor de liquidificador e um de geladeira". (Estudante 4).

"Não, porque são bem parecidos um com outro, por exemplo: motor elétrico do ventilador ou liquidificador". (Estudante 13).

Inferimos que o que eles querem dizer é que ainda se confundem ao diferenciar os motores elétricos nos diversos equipamentos tecnológicos.

"Não saberia, pois não sei qual é um motor de liquidificador ou de batedeira etc.". (Estudante 5).

Dentre todas as respostas, existe uma na qual o estudante declara que é difícil identificar um motor elétrico:

"As vezes pois os motores elétricos são muito complicados de se identificar". (Estudante 3).

Provavelmente ele também se refira à dificuldade em diferenciar os motores elétricos. Apesar de não termos evidências mais contundentes acerca da aprendizagem, pois não fizemos 
uso de nenhuma teoria da aprendizagem nas análises, podemos inferir, por nossa observação participante, que houve uma melhor compreensão do motor elétrico e dos equipamentos que o utilizam.

\section{Compreensão conceitual}

Nesta categoria analisamos as respostas que declaram maior facilidade na compreensão dos conceitos quando introduzidos na discussão do funcionamento de um objeto tecnológico:

"Na minha opinião as aulas de motores elétricos foram as melhores aulas de física porque essa matéria é de fácil compreensão, é uma matéria que prende a atenção do aluno, essa é a melhor matéria de física para se compreender". (Estudante 6).

Nesta resposta percebemos que o motor elétrico provocou uma maior atenção dos estudantes. Foi possível perceber que ao explicar a tecnologia os conceitos científicos ganham mais sentido. $O$ caráter experimental da atividade facilita também a formação de uma imagem mais próxima do pensamento concreto, promovendo uma ponte para a abstração científica:

"Eu gostei mais das [aulas] de motor elétrico, pois não fica muito difícil de imaginar o que é proposto pela teoria e pelo professor. Torna-se mais fácil a imaginação das forças, porque é bem mais visível, além de ter maior interação dos alunos e um maior interesse". (Estudante 9).

$\mathrm{Na}$ afirmação acima o estudante reconhece que a Tecnologia possibilita também um maior diálogo (interação) entre os estudantes o que pode contribuir para a facilitação da compreensão conceitual.

\section{Considerações finais}

Os resultados discutidos neste trabalho indicam que o uso de um objeto tecnológicocomo recurso didático de caráter teórico-experimental numa abordagem problematizadorapossibilita a transformação da curiosidade ingênua em curiosidade epistemológica, facilita o estabelecimento do diálogo problematizador, revela o aspecto aplicado do conhecimento científico e facilita a compreensão conceitual.

A discussão do funcionamento do motor elétrico e suas aplicações desperta a curiosidade (epistemológica) pelos conceitos científicos, mobilizando o esforço cognitivo do estudante. Sua predisposição para interpretar os fenômenos físicos que explicam o funcionamento do motorpossibilitaa aprendizagem. 
O uso de objetos tecnológicos potencializa a dialogicidade, promovendo a aproximação entre professor e estudante, possibilitando uma contínua interação entre os mesmos. Ao discutir objetos que fazem parte do universo cultural dos estudantes se estabelece uma cumplicidade de interesses e o conhecimento científico passa a ser compartilhado.

O aspecto aplicado do conhecimento científico, expresso na Tecnologia, oferece uma justificativa para o seu aprendizado e resgata o caráter experimental da Física, possibilitando a construção de abstrações e evidenciando o compromisso ontológico das teorias científicas. 0 objeto tecnológico auxilia o desenvolvimento da abstração científica por se tratar de um objeto concreto, mediante o qual se constrói uma imagem abstrata, facilitando a compreensão conceitual.

Acreditamos que uma evolução desta proposta educacional seja a utilização de objetos tecnológicos com enfoque nas relações entre Ciência, Tecnologia e Sociedade. Isto permitirá construir conhecimentos e refletir sobre os processos da Ciência e da Tecnologia ciente da necessidade da participação social para a tomada de decisões críticas e ações responsáveis.

Alertamos, porém, que uma atuação docente com este enfoque exige, para seu pleno desenvolvimento, o dispêndio maior de tempo para planejamento, construção dos materiais, preparação das aulas, ou seja, uma dedicação maior e um tratamento didático mais cuidadoso, dado o nível de exigência que as características deste enfoque impõe.

\section{Referências}

ANGOTTI, J. A. P. Solução Alternativa para a Formação de Professores de Ciências. 1982. 188 f. Dissertação de Mestrado (Mestrado em Educação). Faculdade de Educação, Universidade de São Paulo, São Paulo.

ANGOTTI, J. A. P.; DE BASTOS, F. P.; MION, R. A. Educação em Física: discutindo Ciência, Tecnologia e Sociedade. Ciência \& Educação, v. 7, n. 2, p. 183-197, 2001.

ANGOTTI, J. A. P.; DELIZOICOV, D. Física. São Paulo: Cortez, 1991.

AUTH, M. A. et al. Prática educacional dialógica em Física via equipamentos geradores. Caderno Catarinense de Ensino de Física, Florianópolis, v. 12, n. 1, p. 40-46, 1995.

BENDER, A. L.; SBARDELOTTO, D. R.; MAGNO, W. C. Usando motores DC em experimentos de Física. Revista Brasileira de Ensino de Física, v. 26, n. 4, p. 401-405, 2004. 
BOGDAN, R.; BIKLEN, S. Investigação Qualitativa em Educação. Porto, Portugal: Porto Editora, 1994.

BRASIL. PCN+ Ensino Médio: Orientações Complementares aos Parâmetros Curriculares Nacionais. Ciências da Natureza, Matemática e suas Tecnologias. Brasília: MEC, 2002.

CACHAPUZ, A. F. Perspectivas de Ensino. Porto, Portugal: Centro de Estudos de Educação em Ciências, 2000.

DE BASTOS, F. P. Pesquisa-ação emancipatória e prática educacional dialógica em ciências naturais. 1995. 164 f. Tese (Doutorado). Faculdade de Educação, Universidade de São Paulo, São Paulo.

\section{DELIZOICOV, D. Concepção Problematizadora para o Ensino de Ciências na Educação Formal.}

1982. 227 f. Dissertação de Mestrado (Mestrado em Educação). Faculdade de Educação, Universidade de São Paulo, São Paulo.

Conhecimento, tensões e transições. 1991. 214 f. Tese de Doutorado (Doutorado em Educação). Faculdade de Educação, Universidade de São Paulo, São Paulo.

. Problemas e Problematizações. In: PIETROCOLA, M. (Org.). Ensino de Física. Florianópolis: Editora da UFSC, 2005. p. 125-150.

. La Educación en Ciencias y la Perspectiva de Paulo Freire. Alexandria Revista de Educação em Ciência e Tecnologia, Florianópolis, v. 1, n. 2, p. 37-62, 2008.

FREIRE, P. Pedagogia da Autonomia: saberes necessários à prática educativa. 39. São Paulo: Paz e Terra, 2007.

Pedagogia do Oprimido. 47. São Paulo: Paz e Terra, 2008.

GREF, Grupo de Reelaboração do Ensino de Física. Física - Eletromagnetismo. São Paulo: EDUSP, 1995.

MAIA, D. R. A.; MION, R. A. Educação Científica e Tecnológica: a incorporação da Curiosidade Epistemológica no Ensino de Física. In: Encontro Nacional de Pesquisa em Educação em Ciências, V, 2005, Bauru, SP. Atas... Bauru, SP, 2005. 
MENEZES, L. C. Novo (?) Método (?) para Ensinar (?) Física (?). Revista Brasileira de Ensino de Física, v. 2, n. 2, p. 89-97, 1980.

MION, R. A.; ANGOTTI, J. A. P. Investigação-ação e a formação de professores em Física: o papel da intenção na produção do conhecimento crítico. In: Encontro Nacional de Pesquisa em Ensino de Física, IX, 2004, MG - Jaboticatubas. Atas... MG - Jaboticatubas, 2004.

MONTEIRO, M. A. A. et al. As atividades de demonstração e a teoria de Vigotski: um motor elétrico de fácil construção e de baixo custo. Caderno Brasileiro de Ensino de Física, Florianópolis, v. 27, n. 2, p. 371-384, 2010.

MOREIRA, H.; CALEFFE, L. G. Metodologia da pesquisa para o professor pesquisador. Rio de Janeiro: DP\&A Editora, 2006.

MUENCHEN, C.; DELIZOICOV, D. Os Três Momentos Pedagógicos: um olhar históricoepistemológico. In: Encontro de Pesquisa em Ensino de Física, XII, 2010a, Águas de Lindóia. Atas... Águas de Lindóia, 2010.

Práticas de Ensino de Ciências na região de Santa Maria/RS: algumas características.

Revista Brasileira de Ensino de Ciência e Tecnologia, Ponta Grossa, PR, v. 3, n. 2, p. 47-65, 2010b.

PARANÁ, D. N. S. Física. São Paulo: Ática, 2003.

PIETROCOLA, M. Construção e realidade: o papel do conhecimento físico no entendimento do mundo. In: PIETROCOLA, M. (Org.). Ensino de Física. Florianópolis: Editora da UFSC, 2005. p. 0932.

RIBEIRO, K. C.; REZENDE JUNIOR, M. F.; NASCIMENTO, T. G. A Tecnologia como referência dos saberes escolares: um olhar sobre o tema "Geradores Elétricos" nos livros didáticos de Física do Ensino Médio. In: Encontro de Pesquisa em Ensino de Física, XII, 2010, Águas de Lindóia. Atas... Águas de Lindóia, 2010.

RICARDO, E. C. Problematização e contextualização no ensino de Física. In: CARVALHO, A. M. P. (Org.). Ensino de Física. São Paulo: Cengage Learning Edições, 2011. p. 29-51.

RICARDO, E. C.; CUSTÓDIO, J. F.; REZENDE JUNIOR, M. F. A Tecnologia como referência dos saberes escolares: perspectivas teóricas e concepções dos professores. Revista Brasileira de Ensino de Física, São Paulo, v. 29, n. 1, p. 135-147, 2007. 
RICARDO, E. C.; FREIRE, J. C. A. A concepção dos alunos sobre física do ensino médio: um estudo exploratório. Revista Brasileira de Ensino de Física, v. 29, n. 2, p. 251-266, 2007.

ROUXEL, J. Viagem na eletricidade. Título Original: Voyage en électricite. Filme de Animação. Paris: SODEL, Animation Art-graphique Audiovisuel, Electricité de France, 1981. VHS (66 min). Traduzido e distribuído no Brasil pela TV Escola.

SILVA, O. H. M.; LABURÚ, C. E. Motor elétrico de Faraday: uma montagem para Museus e Laboratórios Didáticos. Caderno Brasileiro de Ensino de Física, Florianópolis, v. 26, n. 3, p. 478491, 2009.

VARGAS, M. Técnica, Tecnologia e Ciência. Revista Educação \& Tecnologia, Curitiba, n. 6, p. 178$183,2003$.

Cristina Fátima de Jesus Silva Pires - Colégio Estadual Tancredo de Almeida Neves - Goiânia - GO. E-mail:crispires09@gmail.com.

Paulo Celso Ferrari - Instituto de Física da Universidade Federal de Goiás. E-mail: pcferrari@ufg.br. José Rildo de Oliveira Queiroz - Instituto de Física da Universidade Federal de Goiás. E-mail: rildo@ufg.br. 